\author{
И.П. Вакуленко, В.А. Васильев, К.А. Мурейси, Р.В. Басий, П.А. Лепихов
}

ГОО ВПО «Донецкий национальный медицинский университет имени М. Горького», Донецк

\title{
ОСОБЕННОСТИ УЛЬТРАЗВУКОВОЙ АНАТОМИИ СЕРДЦА В РАННИЕ ПЕРИОДЫ ПОСТНАТАЛЬНОГО ОНТОГЕНЕЗА
}

Сердечно-сосудистая система обеспечивает адекватное кровоснабжение органов и тканей благодаря многоуровневой организации, сложными нейрорефлекторными и нейрогуморальными механизмами. В каждый возрастной период растущего организма она претерпевает изменения, продиктованные физиологической целесообразностью [3].

Вопросам диагностики различных отклонений со стороны сердечно-сосудистой системы у детей раннего возраста посвящено множество работ $[6,10]$. Но, несмотря на их большое количество, в них до конца не раскрыты особенности роста и развития сердца и сосудов, отсутствуют данные постоянного мониторирования и получения количественных данных [8, 9, 11]. Современные методы ультразвуковых исследований сердца дают возможность сравнения функциональных показателей с весом, ростом в ранние периоды постнатального онтогенеза, что является важным в прогнозировании адекватного развития целостного организма и сердечнососудистой системы [7].

Имеющиеся данные ультразвукового исследования сердца детей по ряду параметров во многом являются противоречивыми и не учитывают анатомические особенности сердечнососудистой системы в ранние периоды постнатального онтогенеза.

\section{ЦЕЛЬРАБОТЫ}

Установить возрастные особенности линейных параметров сердца и магистральных сосудов в области его основания у детей на ранних этапах постнатального онтогенеза.

\section{МАТЕРИАЛ И МЕТОДЫ}

Исследования проведены на 260 детях в возрасте от одних суток до трех лет, у которых отсутствовали признаки заболеваний сердечнососудистой системы. Среди них лиц женского пола зарегистрировано 124 и мужского 136. Все дети были разделены на три группы. Первая группа - от одних суток до двадцати восьми дней (ранний и поздний неонатальные периоды), в эту группу вошло 93 исследуемых, из которых 46 девочек и 47 мальчиков, вторая группа - от месяца до одного года (грудной возраст) ее составили 42 девочки и 51 мальчик, и третья от одного года до трех лет (период раннего детства), в ней 41 девочка и 33 мальчика. Методом ультразвукового исследования сердца в М- и B-режимах измеряли и оценивали линейные показатели, такие как: толщина межжелудочковой перегородки (ТМЖП) в систолу и диастолу, конечный диастолический размер левого желудочка (КДРлж), конечный систолический размер левого желудочка (КСРлж), толщину задней стенки левого желудочка (ЗСЛЖ) в систолу и диастолу. При этом вычисляли конечный диастолический (КДО) и конечный систолический объемы (КСО) левого желудочка.

Допплеровским методом исследовали диаметр аортального отверстия, объемы аортального, митрального, легочного потоков, их градиент давления.

Полученные результаты обрабатывали общепризнаннымистатистическимиметодами исследования и заносились в таблицы, данные представлены в виде Me (Q1-Q2), где Ме - медиана, Q1 - первый квартиль и Q2 - третий квартиль. Полученные нами результаты были проверены на нормальность (все три возрастные группы), закон распределения отличается от нормального на уровне значимости $\mathrm{p}<0,05$. Для сравнения величин всех трех групп использовался критерий Крускала-Уоллиса для сравнения нескольких выборок. В ходе исследования был проведен корреляционный анализ Спирмена.

\section{РЕЗУЛЬТАТЫ И ОБСУЖДЕНИЕ}

При анализе линейных показателей сердца было установлено незначительное увеличение

(с) И.П. Вакуленко, В.А. Васильев, К.А. Мурейси,

Р.В. Басий, П.А. Лепихов, 2019

(C) Университетская Клиника, 2019 
показателей толщины межжелудочковой перегородки в диастолу (ТМЖПд) с 0,45 $(0,39-0,5) \mathrm{cM}$ в первой группе до $0,47(0,42-0,5)$ см во второй группе и 0,5 $(0,47-0,56)$ см в третьей группе. Выявлено отличие на уровне статистической значимости $\mathrm{p}<0,01$ между ТМЖПд у детей первой группы и третьей, а также второй и третьей. При этом у задней стенки левого желудочка в диастолу (ЗСЛЖд) с 0,4 (0,35-0,5) см в первой группе до $0,46(0,37-0,5)$ см во второй группе и в третьей группе она достигала 0,52 (0,5-0,62) см. В этот же период, с момента рождения до года, ТМЖПд увеличилась, но всего на 0,02 cм (4,4\%), а с года до трех лет уже на 0,03 см (6,4\%). ЗСЛЖ нарастала с рождения до года на 0,06 см (15\%), а до трех лет на 0,12 см (30\%). Что является статистически значимым на уровне значимости р<0,01.

В систолу эти показатели так же претерпели изменения. ТМЖП у детей первой возрастной группы составила $0,6(0,54-0,62)$ см, второй группе $0,6(0,55-0,67) \mathrm{cm}$ и в третьей $0,72(0,65-$ $0,8)$ см. Таким образом, этот показатель не из- менился у детей с рождения до года, но вырос на 0,12 см (7,2\%) у детей третей группы, т.е. раннего детства $(\mathrm{p}<0,01)$. ЗСЛЖ в общей сложности увеличилась на 0,19 см (34\%) с 0,55 $(0,5-0,6)$ см в первой группе до 0,6 $(0,52-0,67)$ второй группе и до $0,74(0,67-0,85)$ см в третьей группе (табл. 1.$)$

Разница между диастолическим и систолическим размерами левого желудочка у детей первой группы составила - 0,58 см (53\%), что является статистически значимым на уровне значимости $\mathrm{p}<0,01$. У детей второй группы - 0,77 см (36\%), но различие не является статистически значимым и разница в 1,08 см (59\%) у детей третьей группы на уровне значимости р<0,01.

Изменения показателей КДО и КСО представлены в таблице 1. Обращает внимание стойкое увеличение КДО. У новорожденных оно составило 8,13 (6,1-10,5) мл, у детей грудного возраста $15,67(13,2-17,5)$ мл, т.е. отмечено увеличение на 7,54 (54\%) мл (р<0,01) и на 18,33 (94\%) мл увеличилось у детей раннего детства и составило 34 (32-38,8) мл. (p<0,01). Показатель КСО также уве-

Таблица 1. Линейные и объемные показатели структур сердца в группах наблюдения по данным УзИ, Ме (Q1-Q2)

\begin{tabular}{|c|c|c|c|}
\hline \multirow{3}{*}{ Показатели } & $\begin{array}{c}1 \text { группа } \\
\text { n=93 (46 девочек, } \\
47 \text { мальчиков) }\end{array}$ & $\begin{array}{c}2 \text { группа } \\
\text { n=93 (42 девочки, } \\
51 \text { мальчик) }\end{array}$ & $\begin{array}{c}3 \text { группа } \\
\text { n=74 (41 девочка, } \\
33 \text { мальчика) }\end{array}$ \\
\hline & \multicolumn{3}{|c|}{ Возраст } \\
\hline & 1-28 суток & 1-12 месяцев & 1-3 года \\
\hline Вес, кг. & $3,2(2,9-3,5)$ & $5,1(4-7)^{\wedge}$ & $13,5(12-15)$ \\
\hline Рост, см & $52(50-54)^{*}$ & $60(54-65)^{\wedge}$ & $92(84-100)$ \\
\hline ТМЖПд, см & $0,45(0,39-0,5)^{*}$ & $0,47(0,42-0,5)^{\wedge}$ & $0,5(0,47-0,56)$ \\
\hline КДРлж, см & $1,68(1,5-1,83) \#^{*}$ & $2,11(1,91-2,56)^{\wedge}$ & $2,91(2,71-3,18)$ \\
\hline ЗСЛЖд, см & $0,4(0,35-0,5)^{*}$ & $0,46(0,37-0,5)$ & $0,52(0,5-0,62)$ \\
\hline ТМЖПс, см & $0,6(0,54-0,62)^{*}$ & $0,6(0,55-0,67)^{\wedge}$ & $0,72(0,65-0,8)$ \\
\hline КСРлж, см & $1,1(1-1,24)^{*} \#$ & $2,11(1,91-2,56)^{\wedge}$ & $1,83(1,68-1,96)$ \\
\hline ЗСЛЖс, см & $0,55(0,5-0,6)^{*}$ & $0,6(0,52-0,67)^{\wedge}$ & $0,74(0,67-0,85)$ \\
\hline КДО, мл & $8,13(6,1-10,5)^{*} \#$ & $15,67(13,217,5)^{\wedge}$ & $34(32-38,8)$ \\
\hline КСО, мЛ & $2,68(2,07-3,39)^{*} \#$ & $3,84(3,38-4,37)^{\wedge}$ & $15,3(13,6-17,3)$ \\
\hline$\Phi B, \%$ & $0,67(0,64-0,72)$ & $0,68(0,64-0,72)$ & $0,68(0,65-0,73)$ \\
\hline
\end{tabular}

Примечание: Ме - медиана, Q1 - первый квартиль, Q2 - третий квартиль; \# - различия между 1-2 группами являются статистически значимыми на уровне значимости р< 0,$01 ; *$ - различия между $1-3$ группами являются статистически значимыми на уровне значимости $\mathrm{p}<0,01$; $^{\wedge}$ - различия между 2-3 группами являются статистически значимыми на уровне значимости $\mathrm{p}<0,01$. 
личился, но незначительно, с 2,68 (2,07-3,39) мл до $3,84(3,38-4,37)$ мл $(\mathrm{p}<0,01)$ у детей грудного возраста, то есть вырос на 1,16 мл (43\%). И до $15,3(13,6-17,3)$ мл возросло у детей раннего детства, что составило разницу в 11,46 мл (30\%) с детьми грудного возраста и 12,62 (47\%) с новорожденными $(\mathrm{p}<0,01)$.

Исследуемые гемодинамические показатели сердца новорожденных представлены в таблице 2. Как следует из представленных данных, скорость потока, градиент давления имеют тенденцию к увеличению. За исследуемый период аортальный поток в первой группе составил 103 (92,9-116) см/сек, а во второй группе 107 (98,6-117) см/сек, т.е. увеличение состави-

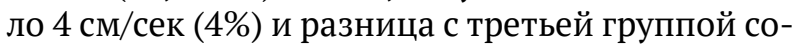
ставила $5 \mathrm{~cm} /$ сек (5\%), но эти показатели не являются статистически значимыми р>0,05. Градиент давления изменился не значительно и составил 4,12 $(3,44-5,5) \mathrm{PmmHg}$ в первой группе, 4,17 (3,74-4,51) PmmHg во второй и 4,43 (3,89$4,79)$ и также не является статистически значимым p>0,05. Митральный поток у новорожденных равен $71(62,9-79,5)$ cм/сек, у детей грудного возраста - 88,7 $(79,4-98,4)$ см/сек, при этом разница между этими показателями составила
17,7 см/сек (25\%). (p<0,01) У детей раннего детства этот показатель равен 95,25 (83,7-109) см/ сек, что на $6,55 \mathrm{~cm} /$ сек $(\mathrm{p}>0,05)$ выше, чем у детей грудного возраста и на $24,25 \mathrm{~cm} / \mathrm{ceK}(34 \%)$, чем у новорожденных $(\mathrm{p}<0,01)$. Градиент давления менялся с 1,97 (1,56-2,52) PmmHg до 3,31 (2,75$3,78)$ PmmHg и 3,72 $(2,96-4,69)$ PmmHg, что свидетельствует о его приросте на 1,34 (7\%) с рождения до года $(\mathrm{p}<0,01)$ и $1,75 \mathrm{PmmHg}$ с рождения до трех лет $(\mathrm{p}<0,01)$. Легочной поток, увеличился с 89,4 $(85,5-95,3)$ cм/сек в первой группе до 94,4 (89-99) см/сек, во второй группе. Соответственно разница между первой и второй составила 5 cм/сек (6\%). В раннем детстве этот показатель составил 98 (89,5-102) см/сек, в этом случае разница между третьей группой и второй составила 3,6 cм/сек (4\%), а разница между первой и третьей 8,6 cм/сек (10\%). Градиент давления в легочной артерии составлял в первой группе детей 3,28 (3,03-3,62) PmmHg, во второй группе - 3,62 (3,44-3,85) PmmHg, и третьей 3,69 (3,3-3,96) Pm$\mathrm{mHg}$, т.е. разница между первой и третьей группой составила 0,41 PmmHg. Показатели потоков правого предсердно-желудочкового отверстия у новорожденных и детей грудного возраста отличались на 4,6 см/сек (7\%) и изменялись с

Гемодинамические показатели аорты, легочного ствола, предсердно-желудочковых отверстий

Таблица 2. в группах наблюдения в доплеровском режиме, Me (Q1-Q2)

\begin{tabular}{|c|c|c|c|}
\hline \multirow{3}{*}{ Показатели } & $\begin{array}{c}1 \text { группа } \\
\text { n=93 (46 девочек, } \\
47 \text { мальчиков) }\end{array}$ & $\begin{array}{c}2 \text { группа } \\
\mathrm{n}=93 \text { (42 девочки, } \\
51 \text { мальчик) }\end{array}$ & $\begin{array}{c}3 \text { группа } \\
\text { n=74 (41 девочка, } \\
33 \text { мальчика) }\end{array}$ \\
\hline & \multicolumn{3}{|c|}{ Возраст } \\
\hline & $1-28$ суток & 1-12 месяцев & 1-3 года \\
\hline $\mathrm{AO}, \mathrm{cm}$ & $1,01(0,9-1,1)^{*} \#$ & $1,26(1,13-1,38)$ & $1,585(1,45-1,72)$ \\
\hline Аортальный поток, см/сек & $103(92,9-116)$ & $107(98,6-117)$ & $108(98,2-115)$ \\
\hline Градиент давления, PmmHg & $4,12(3,44-5,5)$ & $4,17(3,74-4,51)$ & $4,43(3,89-4,79)$ \\
\hline Митральный поток, см/сек & $71(62,9-79,5)^{*} \#$ & $88,7(79,4-98,4)$ & $95,25(83,7-109)$ \\
\hline Градиент давления, PmmHg & $1,97(1,56-2,52) * \#$ & $3,31(2,75-3,78)$ & $3,72(2,96-4,69)$ \\
\hline Легочный поток, см/сек & $89,4(85,5-95,3)$ & $94,4(89-99)$ & $98(89,5-102)$ \\
\hline Градиент давления, PmmHg & $3,28(3,03-3,62)$ & $3,62(3,44-3,85)$ & $3,69(3,3-3,96)$ \\
\hline Трикуспидальный поток, см/сек & $62,6(55,1-66,5)$ & $67,2(61,3-73,6)$ & $63(55,1-70)$ \\
\hline Градиент давления, PmmHg & $1,6(1,34-1,77)$ & $1,77(1,48-2,13)$ & $1,5(1,28-1,7)$ \\
\hline
\end{tabular}

Примечание: Ме - медиана, O1 - первый квартиль, O2 - третий квартиль; \# - различия между 1-2 группами являются статистически значимыми на уровне значимости $\mathrm{p}<0,01 ;$ * - различия между 1-3 группами являются статистически значимыми на уровне значимости $\mathrm{p}<0,01 ;^{\wedge}-$ различия между $2-3$ группами являются статистически значимыми на уровне значимости $\mathrm{p}<0,01$. 
62,6 (55,1-66,5) см/сек до 67,2 $(61,3-73,6)$ см/сек, но уже к трем годам вернулось к первоначальному показателю и равно $63(55,1-70)$ см/сек. Его градиент давления у новорожденных составил 1,6 (1,34-1,77) PmmHg, у детей второй группы, т.е. грудного возраста - 1,77 $(1,48-2,13) \mathrm{PmmHg}$. Разница между показателями этих групп минимальна. И к трем годам этот показатель уменьшился до первоначальных цифр, т.е. 1,5 (1,28$1,7) \mathrm{PmmHg}$. Надо констатировать факт, что показатели легочного и правого-предсердного протока статистической значимости не имеют, также как и их градиенты давления.

Фракция выброса практически не увеличилась и составила $0,67 \%$ в первой группе и $0,68 \%$ у детей второй и третьей групп. Диаметр аорты между первой и второй группами увеличился на 0,25 см $(25 \%)(\mathrm{p}<0,01)$ с $1,01(0,9-1,1)$ до 1,26 $(1,13-1,38)$ см и на 0,575 см $(46 \%)(\mathrm{p}<0,01)$ с рождения до трех лет, что соответствовало 1,585 $(1,45-1,72)$ см.

В ходе исследования была выявлена прямая корреляционная связь (Спирмена) у детей грудного возраста между ТМЖП ростом и весом
$\mathrm{R}=0,376$, а у детей раннего детства связь составила с ростом $\mathrm{R}=0,430$ и массой $\mathrm{R}=0,353$. ЗСЛЖ у детей второй группы и ростом $\mathrm{R}=0,439$ и массой $\mathrm{R}=0,531$. У детей третьей группы связь между ЗСЛЖ и ростом и массой составила $\mathrm{R}=0,357$.У новорожденных связь между КСР и массой равна $\mathrm{R}=0,382$ и ростом $\mathrm{R}=0,484$, а у детей грудного возраста $\mathrm{R}=0,416$. И сильная связь $\mathrm{R}=0,682$ выявлена между КДР и ростом с массой у детей грудного возраста, а у детей раннего детства составили $\mathrm{R}=0,446$ с ростом и $\mathrm{R}=0,386$ с массой $(\mathrm{p}<0,05)$.

\section{В Ы В 0 д Ы}

У детей нарастание толщины межжелудочковой перегородки задней стенки левого желудочка происходит во второй и третьей возрастных группах, а конечный систолический и конечный диастолический объемы левого желудочка увеличиваются в неонатальных периодах, в грудном возрасте и раннем детстве. Давление в аортальном, митральном, легочном и трехстворчатом клапанах, нарастает в первой группе детей, в то время как в раннем детстве оно снижается.

\section{И.П. Вакуленко, К.А. Мурейси, Р.В. Басий, П.А. Лепихов}

ГОО ВПО «Донецкий национальный медицинский университет имени М. Горького», Донецк

\section{ОСОБЕННОСТИ УЛЬТРАЗВУКОВОЙ АНАТОМИИ СЕРДЦА В РАННИЕ ПЕРИОДЫ ПОСТНАТАЛЬНОГО ОНТОГЕНЕЗА}

Сердечно-сосудистая система в каждый возрастной период растущего организма претерпевает изменения. Имеющиеся данные ультразвукового исследования являются во многом противоречивыми, не учитывают анатомические особенности раннего постнатального онтогенеза. Поэтому целью нашей работы является установление возрастных закономерностей развития сердца и магистральных сосудов на ранних этапах постнатального онтогенеза. Были взяты 260 детей в возрасте от одних суток до трех лет без признаков сердечно-сосудистых заболеваний. Их разделили на три группы: первая группа - от рождения и до двадцати восьми дней (ранний и поздний неонатальные периоды), вторая группа - от месяца до года (грудной возраст) и третья от года до трех лет (период раннего детства). Методом ультразвукового исследования в М- и В-режимах измеряли и оценивали линейные показатели такие как толщина межжелудочковой перегородки, конечный диастолический размер левого желудочка, конечный систолический размер левого желудочка, толщину задней стенки лево- го желудочка. Вычисляли такие показатели как конечный диастолический и конечный систолический объемы. Допплеровским методом исследовали диаметр аортального отверстия, скорость аортального, митрального, легочного и трикуспидального потоков, их градиент давления.

В ходе проделанной работы было установлено нарастание линейных параметров сердца, таких как: толщина межжелудочковой перегородки и задней стеки левого желудочка и во второй и третьей возрастных группах. В два раза увеличился конечный диастолический и систолический объем в неонатальных периодах, в грудном возрасте и раннем детстве. Давление в аортальном, митральном, легочном и трикуспидальном клапанах нарастает в первой и второй группах детей, в то время как в раннем детстве оно снижается.

Ключевые слова: ультразвуковое исследование сердца, аорта, легочный ствол, дети от рождения до трех лет. 


\section{I.P. Vakulenko, V.A. Vasiliev, K.A. Mureisy, R.V. Basiy, P.A. Lepihov}

\section{SEI HPE «M. Gorky Donetsk National Medical University», Donetsk}

\section{FEATURES OF ULTRASOUND ANATOMY OF THE HEART IN EARLY PERIODS OF POSTNATAL ONTOGENESIS}

The cardiovascular system in every age period of the growing organism undergoes changes. The available ultrasound data are largely contradictory, do not take into account the anatomical features of early postnatal ontogenesis. Therefore, the aim of our work is to establish the age patterns of the development of the heart and great vessels in the early stages of postnatal ontogenesis. 260 children aged one day to three years without signs of cardiovascular diseases were taken. They were divided into three groups: the first group - from birth to twenty-eight days (early and late neonatal periods), the second group from one month to a year (infant age) and the third group from a year to three years (early childhood period). Using ultrasound in the $\mathrm{M}$ and $\mathrm{B}$ modes, linear parameters such as interventricular septum thickness, end diastolic size of the left ventricle, end systolic size of the left ventricle, thickness of the posterior wall of the left ventri- cle were measured and evaluated. Calculated indicators such as end diastolic and end systolic volumes. The Doppler method investigated the diameter of the aortic orifice, the speed of the aortic, mitral, pulmonary and tricuspid streams, and their pressure gradient.

During the work done, an increase in the linear parameters of the heart, such as the thickness of the interventricular septum and posterior stacks of the left ventricle in the second and third age groups, was found. The final diastolic and systolic volumes increased in the neonatal periods, in infancy and early childhood. Pressure in the aortic, mitral, pulmonary, and tricuspid valves increases in the first and second groups of children, while in early childhood it decreases.

Key words: ultrasound examination of the heart, aorta, pulmonary trunk, children from birth to three years.

\section{ЛИТЕРАТУРА}

1. Агеева М.И, Подзолкова Н.М., Лаврушина Т.В. Комплексное ультразвуковое исследование нормальной анатомии сердца плода. Ультразвуковая и функциональная диагностика. 2010; 3: 18-33.

2. Беспалова Е.Д. Количественные параметры сердечнососудистой системы плода в норме по данным допплер-эхокардиографии. Детские болезни сердца и сосудов. 2007; 3: 79-84.

3. Дворяковский И.В. Ультразвуковая диагностика в неонатологии и педиатрии. Дифференциально-диагностические критерии. Москва: Аир-Арт; 2000. 216.

4. Зотов Д.Д., Гротова А.В. Современные методы функциональной диагностики в кардиологии. СПб.: Фолиант; 2002. 119.

5. Каплунова О.А, Моргунов М.Н, Мирзоян Е.С., Ерошенко А.А. Структура и распространенность малых аномалий развития сердца у детей по данным эхокардиографии. Международный студенческий научный вестник. 2014; 3: 37.

6. Классен А.А. Ультразвуковая анатомия сердца человека на этапах онтогенеза: корреляция анатомических срезов с двухмерными ультрозвуковыми изображениями. Ультразвуковая и функциональная диагностика. 2015; 4: 86.

7. Курдис И.В. Нормальная рентгено-эхокардиографическая анатомия сердца у детей раннего возраста : автореф. дис. ... канд. мед. наук. - М.; 2002. 22.

8. Тарасова А.А, Филюшкина М.Н, Ефимов М.С., Чабаидзе Ж.Л. Ультразвуковая оценка морфофункционального состояния сердца у недоношенных детей в течение первого года жизни. Вестник Российского научного центра рентгенорадиологии Минздрава России. 2013; 3 (13): 6.

9. Школьникова М.А., Осокина Г.Г., Абдулатипова И.В. Заболеваемость, смертность и структура сердечнососудистой патологии у детей в Российской Федерации. Российский медицинский журнал. 2003; 6: 3-6.

10. Ciccone M.M., Scicchitano P., Zito A., Gesualdo M., Sassara M., et al. Different functional cardiac characteristics observed in term/preterm neonates by echocardiography and tissue doppler imaging. Early Human Development. 2011; 87 ( 8) : 555-558.

11. Khositseth A., Nuntnarumit P., Chongkongkiat P. Echocardiographic parameters of patent ductus arteriosus in pre-

\section{REFERENCES}

1. Ageeva M.I, Podzolkova N.M., Lavrushina T.V. Kompleksnoe ultrazvukovoe issledovanie normalnoy anatomii serdtsa ploda [Complex ultrasonic examination of normal anatomy of heart of a fruit]. Ultrazvukovaya i funktsionalnaya diagnostika. 2010; 3: 18-33 (in Russian).

2. Bespalova E.D. Kolichestvennyie parametryi serdechno-sosudistoy sistemyi ploda v norme po dannyim doppler-ehokardiografii [Quantitative parameters of cardiovascular system of a fruit are normal according to a doppler-echocardiography]. Detskie bolezni serdtsa i sosudov. 2007; 3: 79-84 (in Russian).

3. Dvoryakovskiy I.V. Ultrazvukovaya diagnostika v neonatologii i pediatrii. Differentsialno-diagnosticheskie kriterii [Ultrasonic diagnostics in a neonatology and pediatrics. Differential and diagnostic criteria]. Moskva: Air-Art; 2000. 216 (in Russian).

4. Zotov D.D., Grotova A.V. Sovremennyie metodyi funktsionalnoy diagnostiki $\mathrm{v}$ kardiologii [Modern methods of functional diagnostics in cardiology]. SPb.: Foliant; 2002. 119 (in Russian).

5. Kaplunova O.A, Morgunov M.N, Mirzoyan E.S., Eroshenko A.A. Struktura i rasprostranennost malyih anomaliy razvitiya serdtsa $u$ detey po dannyim ehokardiografii [Structure and prevalence of small anomalies of development of heart in children according to an echocardiography]. Mezhdunarodnyiy studencheskiy nauchnyiy vestnik. 2014; 3: 37 (in Russian).

6. Klassen A.A. Ultrozvukovaya anatomiya serdtsa cheloveka na etapah ontogeneza: korrelyatsiya anatomicheskih srezov s dvuhmernyimi ultrozvukovyimi izobrazheniyami [Ultrasonic anatomy of heart of the person at ontogenesis stages: correlation of anatomic cuts with two-dimensional ultrasonic images]. Ultrazvukovaya i funktsionalnaya diagnostika. 2015; 4: 86 (in Russian).

7. Kurdis I.V. Normalnaya rentgeno-ehokardiograficheskaya anatomiya serdtsa $u$ detey rannego vozrasta [Normal X-ray-echocardiographic anatomy of heart at children of early age]: avtoref. dis. ... kand. med. nauk. - M.; 2002. 22 (in Russian).

8. Tarasova A.A, Filyushkina M.N, Efimov M.S., Chabaidze Zh.L. Ultrazvukovaya otsenka morfofunktsionalnogo sostoyaniya serdtsa $\mathrm{u}$ nedonoshennyih detey $\mathrm{v}$ techenie pervogo goda zhizni [Ultrasonic assessment of a morfofunktsionalny condition of heart at premature children within 
term infants. Indian Pediatr. 2011; 48 (10): 773 - 778.

12. Lopez L., Colan S.D., Frommelt P.C., Ensing Gregory J., Kendall Kathleen, et al.Recommendations for Quantification Methods During the Performance of a Pediatric Echocardiogram: A Report From the Pediatric Measurements Writing Group of the American Society of Echocardiography Pediatric and Congenital Heart Disease Council. J. Am. Soc. Echocardiogr. 2010; 23: 465-495. the first year of life]. Vestnik Rossiyskogo nauchnogo tsentra rentgenoradiologii Minzdrava Rossii. 2013; 3 (13): 6 (in Russian).

9. Shkolnikova M.A., Osokina G.G., Abdulatipova I.V. Zabolevaemost, smertnost i struktura serdechnososudistoy patologii u detey v Rossiyskoy Federatsii [ncidence, mortality and structure of cardiovascular pathology at children in the Russian Federation]. Rossiyskiy meditsinskiy zhurnal. 2003; 6: 3-6 (in Russian).

10. Ciccone M.M., Scicchitano P., Zito A., Gesualdo M., Sassara M., et al. Different functional cardiac characteristics observed in term/preterm neonates by echocardiography and tissue doppler imaging. Early Human Development. 2011; 87 ( 8) : 555-558.

11. Khositseth A., Nuntnarumit P., Chongkongkiat P. Echocardiographic parameters of patent ductus arteriosus in preterm infants. Indian Pediatr. 2011; 48 (10): 773 - 778.

12. Lopez L., Colan S.D., Frommelt P.C., Ensing Gregory J., Kendall Kathleen, et al.Recommendations for Quantification Methods During the Performance of a Pediatric Echocardiogram: A Report From the Pediatric Measurements Writing Group of the American Society of Echocardiography Pediatric and Congenital Heart Disease Council. J. Am. Soc. Echocardiogr. 2010; 23: 465-495. 